\title{
Editorial*
}

\section{Reflexões Político-Curriculares sobre a Importância da História das Ciências no Contexto da Crise da Modernidade}

A história das ciências é importante para o aprendizado de estudantes? Esta questão já me foi direcionada inúmeras vezes, feita de uma forma que demonstra a expectativa de uma resposta taxativa, sim ou não, acompanhada de uma espécie de 'certificado de garantia'. Entretanto, em geral me limito a responder depende, o que pode ser um pouco decepcionante à primeira vista. Contudo, nestes momentos convido a uma reflexão sobre por que esta questão envolve diversos fatores, o que nos permite discutir não apenas o papel da história das ciências nas aprendizagens de estudantes, mas também na sociedade em que vivemos, levando-nos a pensar sobre o papel da escola nos dias atuais. Assim, inspirado nestes debates, este ensaio busca cumprir dois objetivos principais: i) mostrar que existem diferentes respostas possíveis à questão que abre este texto e apontar para alguns cuidados que devemos ter quando desenvolvemos propostas educacionais com base na história das ciências; ii) defender que a história das ciências deve assumir novos papéis frente a desafios sociais atuais. Para isso, o texto se organiza em três partes. A partir de reflexões que tomam como base teorias de currículo e historiografia das ciências, busco demonstrar uma pluralidade de papéis para a história das ciências no ensino. A segunda parte aprofunda questões políticas envolvidas no debate e faz um recuo para apresentar uma leitura de nosso tempo a partir do reconhecimento de uma crise da modernidade. Por fim, retorno ao debate sobre o papel político-educacional da história das ciências tomando como referência a crise apresentada.

\section{I) Uma Visão Pluralista da História das Ciências e da Educação ${ }^{2}$}

A maneira mais abrangente de pensar o papel da história das ciências no ensino é discutir o que significa saber uma ciência. Se nos questionam o que é aprender física, por exemplo, a primeira resposta que nos vem à cabeça é o domínio dos conteúdos presentes nos

\footnotetext{
* Recebido: agosto de 2020.

Aceito: agosto de 2020.

${ }^{1}$ Political-Curricular Reflections on the Importance of the History of Science in the Modernity Crisis Context

2 A partir dos anos 90 a discussão sobre o papel da história das ciências no ensino passou a se confundir com os debates sobre natureza da ciência. Estes últimos defendem que a questão 'o que é ciência?' deve ser tratada como um conteúdo específico nos currículos, em especial com o objetivo de fazer com que estudantes superem concepções ingênuas sobre as ciências. Busca-se, então, o estabelecimento de matrizes de referência que delimitem as visões de ciência que devem ser ensinadas. Esta é uma perspectiva curricular que implicitamente adota a lógica das avaliações em larga escala (Noronha, 2018). Aqui defendemos um papel educacional mais diverso para a história da ciência.
} 
programas disciplinares e representados pelos livros didáticos. Contudo, uma reflexão atenta nos leva a perceber tanto que a física, como área do conhecimento, é muito mais do que está nos livros, quanto que um currículo, entendido como um percurso formativo, é muito mais que uma 'ementa'.

Jean-Claude Forquin (2008) afirma que é preciso desnaturalizar os conhecimentos escolares e reconhecê-los como saberes com características epistemológicas próprias, associadas às práticas culturais desenvolvidas nas instituições de ensino. Primeiramente devemos perceber que a ciência escolar é diferente da ciência dos espaços de pesquisa, o que não é negativo, pois permite que saberes escolares tenham características que lhe permitam cumprir objetivos educacionais específicos. Assim, a questão não é negar o processo de didatização de saberes, mas sim reconhecer que há muitas formas de realizá-lo, abrindo a possibilidade para que as ciências sejam aprendidas de outras maneiras. Processos de inovação curricular são complexos e custosos, pois envolvem romper com tradições didáticas já muito enraizadas ${ }^{3}$. Por isso precisamos 'exorcizar' perspectivas enciclopédicas que existem dentro de nós e reconhecer que aprender ciências pode ser muito mais diverso do que em geral consideramos. Nos termos de Douglas Roberts (2007, 1982), devemos reconhecer as diferentes ênfases curriculares que um conhecimento pode ter.

Questionar o que significa saber física deve pressupor que muitas respostas são possíveis, todas elas com sua legitimidade. Realizando-o com algum cuidado, mas sem a pretensão de esgotá-lo, pode-se indicar as seguintes ênfases curriculares: i) Formal: privilegia o domínio dos aspectos formais de uma ciência, em que se espera tanto um pensamento racionalmente estruturado - matematicamente no caso da física - quanto a fluência na resolução de problemas com formulação teórica. ii) Epistemológica-Conceitual: envolve a compreensão dos fundamentos conceituais de uma ciência, na qual a natureza das explicações científicas e das entidades envolvidas nelas são colocadas em debate. Discussões sobre a natureza da luz ou sobre o papel da noção de espaço absoluto na mecânica newtoniana são exemplos desta ênfase curricular. iii) Filosófica-Cultural: reúne discussões sobre as características das ciências e suas relações com outras manifestações culturais. Abrange desde questões sobre a prática científica, isto é, sobre como a ciência produz seu conhecimento, quanto sobre as relações mútuas que as ciências podem ter com a filosofia, as artes, a literatura, as religiões e outras áreas da cultura. iv) Habilidades Científicas: considera que saber física é dominar habilidades típicas da prática científica, como a formulação de hipóteses, a capacidade de investigação, a interpretação de dados científicos, etc. Quando se considera o contexto da escola básica, destaca-se a importância destas habilidades na vida cotidiana. v) Cotidiano: destaca a compreensão do cotidiano como um objetivo em si. Além dos diversos fenômenos físicos presentes em nossas vidas, de um arco-íris ao resfriamento de uma xícara de chá, vivemos em uma sociedade em que cada vez mais os objetos tecnológicos

\footnotetext{
${ }^{3}$ Sobre inovações curriculares ver Pietrocola (2010).
} 
tem papel central. Isso torna importante saber a 'ciência das coisas", de objetos 'simples', como um óculos, a telas de LED. vi) CTSA-QSC ${ }^{5}$ : defende que saber ciências é refletir sobre as relações entre Ciência, Tecnologia, Sociedade e Ambiente (CTSA), transformando este saber em práticas políticas através de uma cidadania ativa. Algumas questões que envolvem a sociedade e exigem a participação de seus agentes podem ser denominadas de sociocientíficas (QSC), pois têm suas raízes nas ciências, como os perigos nucleares, a produção de alimentos transgênicos, o aquecimento global, etc. vii) Identitária: considera que o currículo é um processo de formação de identidades, no qual a construção de relações subjetivas com o conhecimento é um elemento importante. Reconhecendo uma sociedade com diferentes tipos de desigualdades - sociais, de raça, gênero, nacionalidade e outras - é preciso que a aquisição do conhecimento passe pela criação de vínculos identitários, nos quais representatividade importa, o que envolve compreender a ciência como uma atividade multicultural.

A função deste quadro é mostrar que existem diferentes ênfases curriculares que representam diversas formas de saber ciências. É positivo que estudantes passem por diferentes projetos de ensino que trabalhem cada uma dessas ênfases. Contudo, é fundamental que isto seja realizado de forma que os educadores envolvidos tenham clareza de quais objetivos estão sendo cumpridos em cada momento do processo de aprendizagem. A 'pressão do tempo escolar', isto é, as exigências em cumprir muitos objetivos em pouco tempo, nos induz a buscar uma espécie de 'fusão a frio do ensino', na qual buscamos desenvolver da aprendizagem dos aspectos formais à formação de vínculos identitários em uma mesma aula de 45 min. No entanto, parece ser mais adequado reduzir o número de temas e/ou ênfases a serem tratados, possibilitando que cada um seja devidamente trabalhado.

$\mathrm{O}$ reconhecimento das diferentes ênfases curriculares para o ensino de ciências permite uma avaliação ampla do papel da história das ciências. Ele dependerá muito da perspectiva adotada em determinado momento e do tópico a ser trabalhado. Se o objetivo é ensinar a calcular a hipotenusa de um triângulo pelo teorema de Pitágoras, a história deste pensador não terá grande relevância, no máximo como uma motivação inicial que provavelmente não passará de uma anedota. Mas se o que se busca é discutir o papel da geometria na compreensão do mundo, então a abordagem histórica pode ser interessante. Nesta mesma 'linha', compreender as abordagens geométricas utilizadas por Galileu ou Newton na mecânica é um caminho rico para uma abordagem histórica de problemas formais. Contudo, a leitura dos Principia ajuda muito pouco em problemas de estática de corpos

\footnotetext{
4 O GREF - Grupo de Reelaboração do Ensino de Física - foi um projeto que elaborou materiais que se tornaram referência para aprendizagem de física com ênfase no cotidiano. Mais informações: http://fep.if.usp.br/ profis/

5 A educação ambiental pode ser considerada uma ênfase em si, seja pela importância de suas temáticas, seja por suas especificidades, inclusive epistemológicas. Contudo, optou-se pelo CTSA por este balanço ser panorâmico e buscar uma organização que reúna perspectivas. O mesmo vale para as QSC, que tem raízes semelhantes ao movimento CTS, mas em termos curriculares e metodológicos busca caminhos próprios. Para um panorama dos sentidos da educação CTS ver Strieder (2012).
} 
rígidos. Uma abordagem CTS pode estabelecer grande diálogo com a história, por exemplo, em discussões sobre projetos nucleares e seus impactos na política internacional. Mas muitas questões, como as ambientais, são extremamente contemporâneas e uma retomada histórica pode facilmente levar a um distanciamento do problema. Como últimos exemplos, sendo eles todos apenas ilustrativos, pode-se afirmar que praticamente qualquer assunto em uma ênfase filosófico-cultural será bem desenvolvido por episódios históricos; por outro lado, poucas questões do cotidiano exigem este tratamento. Assim, a história das ciências pode ter papel de destaque na aprendizagem de estudantes ou pode simplesmente não ter relevância nas mesmas.

A relação entre história da ciência e ensino prescinde do tratamento de uma segunda grande questão: qual história das ciências levar para as salas de aula? Este é um questionamento que em diferentes épocas abalou o consenso obtido sobre o papel positivo do ensino de história das ciências. Historiadores, em especial, alertam que visões excessivamente simplificadas de episódios históricos podem cumprir o efeito contrário em relação ao esperado na formação de estudantes. Narrativas anedóticas e/ou anacrônicas podem carregar de imprecisões conceituais a visões estereotipadas da atividade científica. Em 1974, Steven Brush já alertava para a importância de professores terem o cuidado de apresentar os episódios a partir de interpretações atualizadas da história das ciências. Se isso era válido há quase 50 anos, o conselho ganha mais importância quando se constata que a historiografia se renovou muito nos últimos anos, em especial passando a considerar as contribuições de diversas culturas e grupos sociais às ciências.

A tese de Thaís Forato (2009) tratou com cuidado, tanto em termos de bases teóricas quanto em relação a práticas educativas, os dilemas de se levar a história das ciências para salas de aula através de abordagens adequadas a jovens estudantes, mas com base em uma historiografia atualizada. Podemos afirmar que na última década houve um grande crescimento dos trabalhos feitos em contextos escolares, o que torna possível supor que hoje sejam os mais presentes na literatura. Por um lado, é digno de comemoração que as pesquisas estejam chegando às salas de aula. Por outro, é importante que neste processo algumas discussões teóricas, mas que têm consequências práticas, sejam mantidas.

As discussões em ensino tenderam a polarizar excessivamente o que seriam historiografias, 'boas' ou 'más', 'adequadas' ou 'inadequadas', 'novas' e 'velhas' e assim por diante. Certamente é importante caracterizar com nitidez o que deve ser evitado como forma de interpretação do passado, mas essas oposições têm levado à construção de uma visão que considera a existência de uma única forma legitima de se interpretar o passado das ciências. $\mathrm{O}$ pressuposto tácito é que não ser anacrônico e/ou positivista e não construir o que Douglas Alcchin denomina de pseudo-histórias (2004) qualifica uma narrativa histórica como válida, tornando-a parte de uma corrente historiográfica. Contudo, se analisamos a literatura especializada é possível verificar que há muitas - e legítimas - formas de se escrever a história das ciências. A coexistência de mais de uma perspectiva historiográfica era evidente 
quando a oposição internalismo e externalismo pautava as discussões em historiografia das ciências. Embora os debates não ocorram mais em torno destes termos, considerá-lo 'superado' é exagero. O que antes era uma disputa entre dois 'times' se converteu em um grande 'campeonato' de escolas de pensamento.

Muitas vezes o termo 'história contextual' é utilizado para caracterizar a historiografia contemporânea. Isto é adequado, pois a preocupação com o contexto talvez seja a principal marca dos trabalhos atuais. Contudo, é possível questionar o que é contexto e qual o seu papel das explicações históricas ${ }^{6}$. Esta é uma questão delicada, pois uma mesma obra, personagem ou prática científica coletiva está imersa em diferentes contextos. $\mathrm{O}$ contexto científico é delimitado por aqueles que produzem o conhecimento e que trabalham com semelhantes pressupostos teóricos e metodológicos, que desenvolvem práticas de mesma natureza e que colaboram ou concorrem entre si. Há um microcosmo comum que une estes atores. Pode-se também pensar em um ambiente intelectual mais amplo, onde se verifica influências mútuas entre cientistas de diferentes áreas, mas também entre cientistas e artistas, ou, por exemplo, as inspirações de um físico ocorrida pela leitura de uma obra filosófica. Este contexto pode se ampliar para um plano cultural mais amplo e etéreo, em que o contexto é formado por desde imaginários quanto comportamentos coletivos. Além destes, pode-se pensar em contextos macros, que envolvem diferentes organizações e hierarquizações sociais, variadas formas de governo e agentes políticos e, finalmente, modos de produção e circulação de mercadorias, isto é, o contexto econômico ${ }^{7}$.

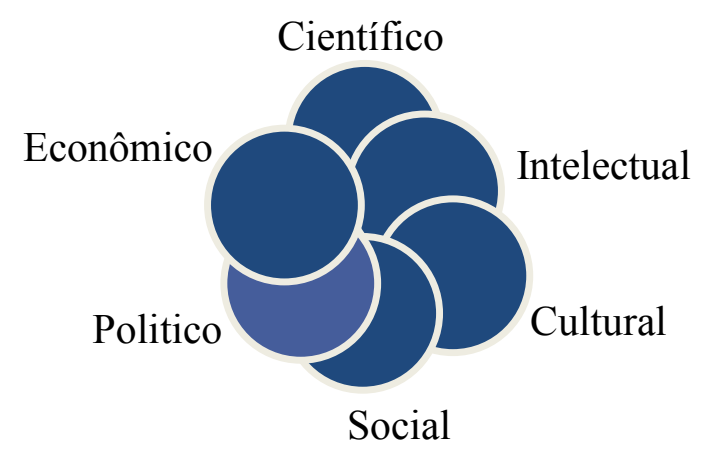

Fig 1 - Representação de diferentes contextos em que a ciência se insere.

Esta esquematização nos ajuda a levantar algumas questões: estes diferentes contextos - científico, intelectual, cultural, social, político e econômico - estão presentes na prática científica da mesma forma? Eles sempre desempenham o mesmo papel na construção das ciências? Quando investigamos diferentes episódios da história das ciências percebemos

\footnotetext{
6 Peter Galison (2008), em seu 'balanço' Ten Problems in History and Philosophy of Science, considera a pergunta 'o que é contexto?' como umas das importantes a serem tratadas.

${ }^{7}$ A discussão sobre historiografia realizada nesta seção é detalhada em Gurgel e Watanabe (2020).
} 
que em cada um deles algum desses contextos pode ter sido preponderante. Por exemplo, quando se estuda a história das máquinas térmicas o contexto econômico é determinante; a compreensão da fissão nuclear passa pelo contexto político da $2^{\mathrm{a}}$ Guerra Mundial, culminando na produção das primeiras bombas atômicas; a gênese da teoria da relatividade pode ser associada, como mostrou Galison (2003), às mudanças sociais da virada do século XIX ao $\mathrm{XX}$, enquanto a mecânica quântica se insere no contexto da cultura da República de Weimar [a chamada tese de Forman (1971)]; a eletrodinâmica nasce com Oersted a partir do meio intelectual em que a nathurphilosophie era discutida; por outro lado, Dirac é um exemplo de personagem que produz seus trabalhos influenciados por questões postas pelo campo científico.

Cada um dos exemplos anteriores poderia ser desenvolvido de modo a demonstrar que os mesmos dão margem a interpretações que valorizam contextos que não os citados. Isso apenas reforça o ponto principal da discussão apresentada, há muitas historiografias das ciências e esta pluralidade precisa ser reconhecida. Esta é uma diversidade que não é aleatória e não se trata de um "tudo vale". Cada uma delas reflete posturas teórico-filosóficas específicas. Por exemplo, determinadas formas de se valorizar o contexto econômico, associadas a como se dão os processos de produção material, constituem uma historiografia marxista. Por outro lado, histórias culturais das ciências valorizam como as práticas e modos simbólicos de construção de significados se dão, nas quais se privilegia uma delimitação espaço-temporal muito grande dos episódios. Histórias políticas, sociais, ou epistemologiashistóricas, contrõem os episódios e as formas de estudá-los de modos próprios, inclusive na escolha de quais fontes privilegiar e como analisá-las.

Nosso 'espirito conciliador' sempre nos impele a querer uma unidade quando se depara com a diversidade. Então, quando percebemos que um episódio histórico pode ser analisado a partir de diferentes perspectivas, nosso primeiro impulso é o de tentar esboçar uma possível narrativa que consiga perpassar todas elas . Não posso afirmar que isso é impossível, mas é digno de confiança considerar que é preciso ter enorme cuidado quando se busca agregar em uma mesma narrativa diferentes olhares. Posicionamentos teóricometodológicos, quando analisados a partir de suas bases filosóficas, muitas vezes são constituídos por meio de oposições de uns em relação aos outros. Isto significa que conciliálos pode levar a grandes incoerências, o que evidentemente deve ser evitado. Este alerta não proíbe a criatividade e não deve constranger a busca de novas formas de interpretação, mas deve-se ter em conta que novos caminhos envolvem ressignificar projetos filosóficos.

\footnotetext{
8 A primeira vez que formulei a figura 1 criei uma representação em que os exemplos de diferentes contextos formavam camadas, como uma cebola. O contexto científico era a camada mais interna, seguido do intelectual, cultural, social, político e, finalmente, econômico. Esta representação 'aristotélico-ptolomaica' é limitada. Ela hierarquiza os contextos como se suas diferenças fossem apenas uma questão de escala, do mais 'interno' ao mais 'externo'. Assim, ela nos leva a pensar que estes 'níveis' podem ser 'varridos' formando uma totalidade coerente. A imagem adotada buscou mostrar que cada um deles tem uma 'independência' e que quaisquer interfaces são parciais.
} 
Anteriormente destacamos a necessidade de se ter clareza sobre qual ênfase curricular se está trabalhando, isto é, qual objetivo se busca cumprir quando se opta (ou não) por uma abordagem histórica. O segundo grande alerta consiste no compromisso em se buscar uma historiografia adequada à ênfase adotada. Se, por exemplo, o objetivo é ensinar física nuclear em uma perspectiva CTS, uma história política com destaque às relações internacionais é a historiografia que mais se adequa. Por outro lado, uma ênfase epistêmicoconceitual combina muito mais com abordagens de epistemologia-histórica (ou mesmo a um 'internalismo' aos modes de Alexandre Koyré). Quando enunciado, este alerta parece uma obviedade; contudo, é muito comum em monografias, dissertações e teses a falta de clareza nos objetivos educacionais e, consequentemente, na historiografia adotada. Muitos trabalhos de pesquisa realizam bons mapeamentos sobre os potenciais da história das ciências no ensino, mas acabam pecando por não se posicionar frente a eles. Educar é fazer escolhas, em alguns momentos individualmente, em outros coletivamente. Por isso a educação é um ato político e 'despolitizá-la' implica em sua negação.

\section{II) Ciência e Educação na Crise da Modernidade}

Antes de retomar a discussão sobre história das ciências no ensino é importante colocar uma questão mais fundamental: por que ensinamos ciências nas escolas? Esta questão é estruturante de qualquer debate sobre educação em ciências e é preciso ter consciência do que ela envolve. Primeiramente, deve-se ter claro que a resposta não pode se limitar a uma valoração intrínseca das ciências, por exemplo, de suas qualidades epistemológicas. Discutir por que ensinar ciências é propor um projeto de sociedade, situando o papel do conhecimento científico nele e ponderando quais saberes suas cidadãs e cidadãos devem adquirir. É importante notar que não há respostas definitivas a esta questão, isto é, não há uma razão com importância suficiente para fazê-la sobreviver ao tempo, permitindo que as motivações pelas quais ensinávamos ciências há algumas décadas não sejam as mesmas de hoje.

Quando nos deparamos com o desafio de propor um modelo de sociedade é comum sermos tomados por um ímpeto idealista e darmos início ao projeto de uma nova 'Atlântida'. Ideais são necessários, mas precisamos saber lidar com eles. A atuação política envolve utopias, isto é, a capacidade de 'desnaturalizar' o que é social e verificar que a sociedade pode ser diferente; projeto que se completa pela defesa de princípios éticos. É o que está em jogo quando nos referimos a uma sociedade mais justa e igualitária. Assim, uma utopia não é algo ideal no sentido de impossível ou inalcançável, mas sim um 'farol' que guia um caminho a ser percorrido. Contudo, considerar que podemos nos aproximar de um ideal não pode ser confundido com a ideia que de as lutas políticas não serão mais necessárias um dia. Uma sociedade com algum tipo de organização é fruto de um processo político custoso e os equilíbrios alcançados são instáveis; pequenas ações os desfazem. Isso exige compreender a sociedade como um sistema dinâmico, em constante mudança, na qual seus agentes precisam 
estar constantemente atuando. Então, um projeto político não pode se limitar às suas utopias, é preciso conhecer em detalhe a sociedade presente e planejar ações em relação ao status quo.

É tarefa inglória caracterizar em poucas linhas o estado em que o mundo se encontra e indicar pontos de enfrentamento. Muitos pensadores adotam perspectivas que o contrapõe à modernidade e esta pode ser considerada uma boa referência para a discussão. $\mathrm{O}$ termo mais famoso e polêmico é o de Jean-François Lyotard (1986), pós-modernidade, que indica uma mudança ou ruptura em relação à modernidade. Entretanto, há outras propostas que reconhecem que nossa época nos trouxe novas questões, mas as veem como consequências da modernidade, como a modernidade líquida de Zygmunt Bauman (2001) ou a modernidade reflexiva/tardia de Anthony Giddens (1991).

Em sociologia, diferentes dos historiadores, o período moderno compreende de meados do século XVIII aos anos 80 do século $\mathrm{XX}^{9}$. Em relação às estruturas macrossociais, esta denominação representa as sociedades que se industrializaram e urbanizaram neste período, no qual o capitalismo se tornou hegemônico. $\mathrm{O}$ projeto político associado à modernidade é o da garantia das liberdades individuais e da igualdade entre cidadãos, em um sistema em que o povo detém o poder, isto é, um regime democrático. Este projeto somente se sustenta se houver um cosmos social, isto é, caso se construa meios para que a sociedade funcione de modo organizado.

As dimensões e papéis do estado são um dos elementos que mais diferencia posições políticas; por exemplo, uma socialdemocracia defende uma maior intervenção do estado, enquanto uma democracia liberal opta por um estado mínimo e um sistema econômico-social autorregulado. Contudo, em ambos os casos, a existência de diferentes tipos de instituições é fundamental à manutenção da democracia. Primeiramente por elas garantirem acesso ao que é público, de direitos a bens comuns, como o conhecimento. Mas, além disso, o bom funcionamento de uma instituição republicana tem como base o estabelecimento de procedimentos que se sobreponham às vontades ou interesses individuais, o que garante a justiça e permite que a sociedade não sucumba ao autoritarismo.

Do ponto de vista filosófico, a modernidade é um projeto iluminista, no qual a crença, valorização e defesa da razão é um dos seus pilares. No século XVIII, o das luzes, Jean le Rond d'Alembert e Dennis Diderot (1989) editaram a Encyclopedie ou Dicionário Raciocinado das Ciências das Artes e dos Ofícios por uma Sociedade de Letrados. Para esses autores, o conhecimento não era somente o guia para uma sociedade melhor, mas também o caminho para a felicidade. A razão como 'faculdade da alma', isto é, como uma capacidade presente nos pensamentos dos sujeitos, é um pressuposto importante para visões liberais. Estas, em termos muito gerais, defendem que os seres humanos, caso lhe sejam dadas as condições mínimas necessárias, desenvolvem-se o mais plenamente possível. Interferências

\footnotetext{
${ }^{9}$ A periodização em história define o período moderno como posterior ao medieval, a partir de meados do século XV, e anterior ao contemporâneo, que tem a revolução francesa, em 1789, como marcadora. Para uma discussão dos conceitos de modernidade e pós-modernidade ver Giddens e Sutton (2015).
} 
externas neste processo seriam constrangimentos que limitariam as realizações individuais. Por outro lado, a racionalidade também pode ser pensada como guia e fruto de trabalhos coletivos, nos quais, por exemplo, debates públicos levam a melhores decisões. Por fim, vale destacar que as ciências e a educação são projetos fundamentalmente modernos. A primeira aposta na racionalidade e em outros valores epistêmicos associados a ela; a verdade, a objetividade etc. A segunda é uma instituição típica da modernidade, que busca racionalizar tanto os saberes quanto suas formas de difusão e apropriação.

Diversos problemas, da crise ambiental à pandemia de fake news, abalam a confiança na modernidade, seja ela como projeto, seja como realidade concreta. Dificilmente algum analista negue a crise da modernidade, no entanto, autores dos mais diversos campos - e que tratam o tema mais ou menos diretamente - acabam se localizando em um espectro que considera posições que variam desde a crítica e abandono de seus princípios fundantes, à defesa de suas bases, mas com o reconhecimento de uma necessidade de reformá-la. No primeiro caso, por exemplo, temos Bruno Latour (2019), que tem buscado desenvolver uma nova epistemologia, enquanto Hürgen Habermas (1992) considera ser muito cedo para abandonar a modernidade, mantendo seu projeto de razão comunicativa.

A ideia de modernidade ganhou força no século XIX, quando os ideais de progresso se tornaram referência, algo bem sintetizado na filosofia de Auguste Comte (2020). Contudo, em especial a partir da $2^{\mathrm{a}}$ Guerra Mundial, este ideal começa a desmoronar, movimento descrito por Nicolau Sevcenko (2001) como uma montanha russa. As bombas atômicas revelaram o lado 'sombrio' das ciências, que foi reforçado pelo reconhecimento dos impactos negativos à saúde e ao meio ambiente de produções científicas. O livro Primavera Silenciosa, escrito por Rachel Carson (2010) e lançado em 1962, é uma obra que marca a história dos movimentos ambientais ao mostrar os efeitos de pesticidas. Para além do caso ali tratado, sua repercussão fez com que se passasse a desconfiar das 'soluções científicas' a diversos problemas da sociedade. Mesmo que hoje se critique alguns pontos apresentados pela autora, o livro acabou se tornando um emblema da necessidade de se pensar os impactos da ciência e tecnologia na sociedade. Ao longo dos anos esta preocupação apenas aumentou devido a interesses vinculados à produção científico-industrial. Do tabaco ao monopólio das tecnologias avançadas, passando por uma indústria farmacêutica com preocupação redobrada às necessidades dos mais ricos, a não-neutralidade das ciências foi ao longo do tempo revelada.

Ao mesmo tempo em que as crenças nas ciências se abalavam ao longo do século $\mathrm{XX}$, a epistemologia acumulava reflexões que acompanhavam esta crise. Considerar a ciência digna de confiança envolve reconhecer nela distinções epistemológicas; a conquista de uma verdade objetiva foi uma espécie de promessa que a ciência fez à sociedade. Entretanto, se a modernidade nos remete ao iluminismo, desde aproximadamente esta época a objetividade já está em questão. Aylesworth (2015) localiza em Immanuel Kant um dos antecedentes mais antigos da pós-modernidade por este autor ter desenvolvido uma filosofia que, apesar de 
racionalista, nega a possibilidade de conhecermos os objetos em si. Pensadores muito distintos como Karl Marx, Friedrich Nietzsche e Martin Heidegger são incluídos nesta lista por de alguma forma terem apontado para fragilidades dos pressupostos hoje chamados de modernos. Contudo, a formulação que mais representa o 'fim' da modernidade é o chamado abandono das grandes narrativas, conforme proposto por Lyotard (1986). Há um afastamento da ideia de universais na sociedade e não haveria um eixo que pudesse ser considerado o estruturante da história.

A filosofia das ciências se manteve relativamente afastada dos debates sobre a modernidade, mas é válido notar que o que prevaleceu ao longo do século XX foi um discurso de desconstrução crítica dos fundamentos que davam legitimidade às ciências. Paul Feyerabend chegou a ser chamado de o pior inimigo da ciência por seu Contra o Método (2011), embora posteriormente tenha ficado claro que sua proposta nunca foi contra $a$ ciência. A busca de uma compreensão da 'ciência como ela é' fez prevalecer posturas construtivistas em relação à mesma. Este movimento, por um lado, permitiu grandes avanços em relação à compreensão da prática científica. Contudo, os estudiosos das ciências deixaram a sociedade carente de um discurso que a valorizasse ${ }^{10}$.

A crise da modernidade não se restringe a uma crise das ciências e envolve diferentes níveis de organização da sociedade. O sistema capitalista, por mais que mantenha seus apoiadores, não consegue mais esconder suas falsas promessas e contradições internas. $\mathrm{O}$ denso estudo de Thomas Piketty (2014) demonstrou que as desigualdades vêm aumentando ao longo da história do período industrial. Seus dados se materializam em situações desumanas que aprendemos a conviver, como a falta de moradia, alimentação e acesso à educação e à saúde. Se crises como a de 2008 deixam explícito o absurdo da falta de regulação do mercado financeiro, levando alguns a supor que este poderia ser o 'princípio do fim' para o capitalismo como o conhecemos, relatórios como os da Oxfam mostram que a concentração de renda continua a crescer e que meia dúzia de brasileiros, literalmente, detém uma riqueza equivalente ao patrimônio dos 100 milhões mais pobres do país ${ }^{11}$.

Contudo, a oposição à modernidade também é crise que leva à criatividade. Movimentos artísticos, que tipicamente se colocam na vanguarda, buscaram se reinventar indo 'além da estética da modernidade'. Não se busca mais a produção dentro de um estilo pré-definido, optando-se por uma mistura de gêneros, muitas vezes com grandes pitadas de ironia. Não se trata apenas de buscar novas formas de representação, os suportes materiais convencionais, como telas, mármores, etc, são abandonados. Faz-se arte com sucatas, ou o próprio corpo do artista é o 'suporte' para performances que buscam expressar as

\footnotetext{
10 Muitas vezes autores que desidealizaram as ciências são acusados de responsáveis pela existência de movimentos anti-ciência. Esta parece ser uma acusação injusta, pois seus discursos não circulam amplamente na sociedade. Contudo, o vazio em relação a um discurso comum sobre a validade das ciências, algo de responsabilidade de quem se dedica ao seu estudo, faz com que seja difícil se contrapor a tais movimentos.

$11<$ https://www.oxfam.org.br/um-retrato-das-desigualdades-brasileiras/a-distancia-que-nos-une/> .
} 
subjetividades que não podem ser representadas. Ao mesmo tempo, as novas tecnologias de informação e comunicação tiram materialidade da própria vida cotidiana. Se no passado filmes de ficção científica já buscavam produzir estranhamento através de cenas em que pessoas conversavam por meio de projeções de suas imagens, seus autores não imaginavam que as pessoas passariam a se apaixonar por meio de redes sociais. O hiper-realismo é proposto como uma das categorias que representa o nosso tempo. Ligado a isso há uma radicalização do processo de individualização, no qual a sociedade parece espelhar nossa compreensão do universo e admitir que o centro está em toda parte. Assim, não parece ser exagero afirmar que nossa cultura passa por grandes modificações nos últimos anos.

Conforme apontado anteriormente, alguns autores dão mais ênfase às rupturas enquanto outros enxergam mais continuidades em relação ao que podemos chamar de uma modernidade clássica e uma nova ou pós-modernidade. De toda forma, parece sempre prevalecer interpretações que contrapõem duas eras, que inclusive podem ser datadas historicamente, marcando-se o fim de uma e o início da outra. Penso ser possível tratar a questão de outra forma, que evita essencializar uma época por meio de 'retratos' que buscam defini-la. Talvez o mais importante seja captar dinâmicas que têm movido alguns setores da sociedade e, com isso, compondo a história.

Afirmar que o projeto de modernidade se realizou parcialmente não significa desconsiderá-lo como estruturante do mundo em que vivemos. Mesmo autores que optam pelo termo pós-modernidade admitem isso. Assim, não parece ser um bom caminho tratá-lo como algo que já foi superado. Prefiro defender que o caráter inconcluso da modernidade permitiu a realização de sua antítese. Este contraponto à modernidade reúne tanto sua negação, quando se critica a validade de suas bases, quanto seus limites, quando seus princípios são aceitos, mas se denuncia o que e quem ficou de fora deles. Assim, fenômenos sociais que vivemos podem ser interpretados a parir de uma tensão entre o moderno e o pósmoderno.

Oposições às ciências sempre existiram, das mais ponderadas às mais conspiratórias; da mesma forma que notícias falsas não nasceram com o WhatsApp. Contudo, sempre foi parte do projeto de modernidade estabelecer quais conhecimentos devem ser valorizados socialmente. Instituições como as universidades, mesmo que criadas na idade média, cumpriram papel fundamental no projeto de modernidade como centro de gerenciamento e controle da produção e difusão do conhecimento. Seu papel de definição do conhecimento válido e de seu papel social é bem demonstrado através dos diplomas, que certificam que um sujeito adquiriu determinados saberes e pode exercer, por meio deles, funções na sociedade. Este capital cultural institucionalizado, nos termos de Pierre Bourdieu (2015), também atribui status que garante que alguns sujeitos sejam reconhecidos como mais legitimados para emitir opiniões. É válido destacar que o 'império das universidades' ocorre por elas terem obtidos os recursos para a produção e difusão de seus saberes. Atividades que exigem muito investimento acabam se concentrando em poucos espaços, o que facilita seu gerenciamento. 
No entanto, a tecnologia, fruto da ciência moderna, permite uma enorme facilidade para criação de conteúdos que podem circular amplamente e sem restrições. Livros que no passado eram bens de luxo, hoje podem ser impressos a custos baixos. A circulação de textos em versão eletrônica pode ser considerada algo revolucionário, pois em uma questão de segundos um artigo pode estar à disposição do mundo todo. Neste contexto, as mídias se ressignificam; vídeos e áudios ganham novos papéis sociais, inclusive conquistando 'espaços' restritos aos textos. Um entusiasta modernista concluiria que a tarefa de uma socialização plena do conhecimento, elemento fundamental para uma sociedade justa e igualitária, estaria então prestes a ser concluída. Só que não!

Holden Thorp (2020), editor chefe da prestigiada revista Science, afirmou em editorial publicado em 26 de junho que a comunidade científica está perdendo a batalha contra o que ele chamou de desinformação. A pandemia do COVID-19 tornou mais claro do que nunca que existe uma batalha ocorrendo e que os cientistas, grupo representante da modernidade, precisam fazer seu papel de agentes históricos. Mas, para isso, é necessária uma compreensão clara do problema a ser enfrentado. As fake news, compreendidas como afirmações manipuladas intencionalmente, são graves pelo seu potencial político devastador. O fato de poderem definir eleições faz com que atualmente sejam debatidas em todo o mundo, tornando-as o maior desafio legislativo contemporâneo ${ }^{12}$. No entanto, as fake news, compreendidas desta forma, são somente a ponta de um iceberg muito maior e mais complexo.

As formas de produção e circulação do conhecimento da pós-modernidade têm estabelecido novas formas de legitimação. Enquanto um acadêmico moderno reivindica sua autoridade, por exemplo, apresentando-se como doutor, um influenciador digital se legitima citando seus milhares de seguidores. Quem aceitou as regras do jogo acadêmico se enfurece frente a esta situação, negando a legitimidade de seu 'oponente'. Pesquisadores ridicularizam 'teóricos da internet', julgando-os com suas próprias métricas, sem perceber que a população que paga seus salários não compartilha de suas formas de avaliação. Não apenas empresas contratam consultores que não tem 'currículo lattes', mas hoje instituições de ensino fazem propaganda destacando que seu corpo docente conta com pessoas que adquiriram prestígio por sua presença nas redes sociais. Intelectuais modernos vêm perdendo seu espaço na arena pública e, no mínimo, é preciso reconhecer que este espaço é importante ${ }^{13}$.

\footnotetext{
12 Não deixa de ser notável que os fenômenos sociais pós-modernos gerados a partir das novas tecnologias de informação e comunicação estejam se transformando em uma velocidade que é superior à associada aos intervalos de tempo necessário à produção de leis com participação da sociedade civil organizada (prática típica da modernidade).

${ }^{13}$ Em uma mesa no Encontro da Licenciatura do IFUSP de 2019 uma história simples, mas representativa para esta situação, foi apresentada. Um grupo de graduandos e pós-graduandos em astronomia criou o canal Astrotubers. Um de seus membros fez um relato sobre visitas a escolas para falar sobre astronomia. Quando se apresentavam como pesquisadores da universidade não viam reação dos ouvintes. Mas, quando mostravam seu canal e o número de seguidores os jovens se mostravam entusiasmados em ouvi-los, incluindo pedidos de selfs ao final.
} 
Não tenho a pretensão de tornar esta leitura de nosso tempo - a tensão entre modernidade e pós-modernidade - em uma 'grande narrativa', o que seria excessivamente moderno. Contudo, ela pode ser útil para além das questões em torno do conhecimento. $\mathrm{O}$ papel da mídia na sociedade se tornou um debate atual. Outrora denunciada por teóricos críticos como um $4^{\circ}$ poder com grande potencial de manipulação, busca-se hoje reposicionála no projeto de modernidade como garantidora da transparência política. Um segundo exemplo se refere à justiça. Ao mesmo tempo em que nos revoltamos com abusos de poder por parte de advogados, juízes ou promotores, torcemos para que a lei prevaleça ou para que o Supremo Tribunal Federal faça com que se honre a constituição e impeça algum desgoverno.

\section{III) Um Papel Político para a História das Ciências}

A escola, com suas virtudes e defeitos, é um projeto moderno. Embora considere que a realidade que hora se impõe exija que ela se reveja, penso que seu papel ainda deve se manter do lado da modernidade. Não se trata de uma defesa de uma superioridade da modernidade, mas sim da busca de equilíbrio na composição de pares que se colocam na sociedade. A pós-modernidade está conquistando seu espaço independente da escola tradicional, o que permite defender que esta cumpre melhor papel se mantendo do lado em que está.

Um dos maiores perigos advindos da facilidade de produção e circulação de saberes é a formação de 'curtos-circuitos' que levam à criação de bolhas sociais que se autoalimentam. Esta é a verdadeira natureza das fake news. Tratá-las pelo viés positivista que se limita a compreendê-las como afirmações que não correspondem à realidade é muito pouco. Como muitos estudos sociais e culturais dos conhecimentos mostram, a produção da verdade passa por círculos sociais de validação ${ }^{14}$. Os curtos-circuitos de informação negam o caráter público do conhecimento, permitindo que as pessoas se fechem em suas crenças. A defesa do homeschooling, que vem ganhando força, é um grande sintoma deste processo, que passa por elementos mais sutis como os projetos de vigilância sobre o que é ensinado. A escola precisa ser o espaço de rompimento destas bolhas, em que estudantes se engajem em diálogos em que múltiplas visões de mundo possam ser apresentadas. Quando as diferenças se tornam antagonismos, o diálogo cessa e as soluções se tornam mais difíceis. Se a escola tem a função de preparar para a vida, aprender a lidar com as diferenças através do diálogo talvez seja o ponto fundamental.

A ciência é uma das áreas que mais tem a aprender quando se trata de diálogo. Seus representantes pouco se comunicam com a sociedade e quando o fazem optam pelo monólogo. Não há problema algum em defender a legitimidade das ciências; entretanto, a era

\footnotetext{
14 Contudo, para não cair em um relativismo simplista, é importante notar que diferentes microcosmos sociais podem ter dinâmicas de funcionamento com comprometimentos diferenciados em relação às verdades que produzem. Um dos principais autores que tratou desta questão foi Pierre Bourdieu. Sobre isso, ver Watanabe (2015) e Gurgel e Watanabe (2020).
} 
da catequese científica precisa acabar. A mudança aqui proposta é sutil, mas pode ser determinante no processo. Ensinar precisa ser mais do que fazer estudantes entenderem as 'verdades das ciências'; precisamos justificá-las. Não é certo e nem prático pressupor que jovens precisam estar dispostos a acreditar nas ciências. Assim, é preciso que se ensine porque as pessoas que se dedicam às ciências consideram certos saberes válidos. $\mathrm{O}$ conhecimento deve ser apresentado junto com seu contexto de produção. Com isso, voltamos ao papel da história das ciências no ensino. Ela é o principal meio de apresentar o processo de construção das ciências. A conclusão em si não é nova, mas chegar a ela por novos caminhos nos permite qualificá-la. O elemento importante é a defesa de um papel político para a história das ciências, que passa a ser pensada como um instrumento de transformação ${ }^{15}$.

Por vivermos um momento em que as ciências estão sob pressão, tendemos a querer produzir discursos que a idealizam sob a alegação que suas fragilidades não podem ser reveladas. Acredito no oposto; precisamos apresentar as ciências argumentando porque elas podem ser consideradas importantes mesmo com todas as suas fragilidades. Por isso, de uma parte, tenho adotado os sciences studies como perspectiva teórico-metodológica por ela buscar mostrar, na medida do possível, a ciência como ela é, a desnaturalizando, a desessencializando e a desidealizando ${ }^{16}$. Embora esta área trate de questões epistemológicas, não é seu objetivo formar uma epistemologia. Por isso, entendo ser necessário apelo a autores próprios desta área e algumas pesquisas têm adotado o realismo crítico - em especial os realismos estrutural e perspectivo - e o racionalismo histórico de tradição bachelardiana ${ }^{17}$. Em termos muito gerais, estas são linhas que reconhecem as dimensões humanas das ciências, tanto as individuais quanto as coletivas, abandonando o objetivismo, mas tentando manter a objetividade com um valor importante às ciências. Assim, de modo moderado, busca-se defender uma especificidade epistemológica das ciências para que ela justifique seu papel frente à sociedade.

Quando afirmamos que a história permite humanizar as ciências, para que esta ação não seja uma idealização disfarçada dela, é preciso que seus aspectos mais constrangedores e polêmicos também sejam revelados. Assim, é preciso que se discuta questões éticas, da produção de uma bomba aos preconceitos presentes no ambiente científico, que ainda exclui pessoas por raça, gênero ou sexualidade. Um dos maiores limites da modernidade foi o de ter se desenvolvido de modo eurocêntrico e colonizador. Como argumenta Ortiz (2015), uma das marcas de nosso tempo é a convivência intensa de muitas culturas. Então, é preciso que as ciências sejam apresentadas demonstrando esta diversidade.

\footnotetext{
15 Vale destacar que esta não é apenas uma proposta do grupo de pesquisa que coordeno. O Núcleo de Investigação em Ensino, História da Ciência e Cultura (NIEHCC-CEFET/RJ), sob liderança de Andréia Guerra, tem produzido as contribuições mais importantes nesta linha de pensamento. https://niehcc.wordpress.com/

16 Para um bom panorama sobre science studies ver Pestre (2006).

17 Sobre realismo crítico ver Noronha (2014). Sobre a tradição bachelardiana ver Milnitsky (2018).
} 
Por fim, uma das linhas de investigação do grupo de pesquisas é denominada 'Imaginário e Circulação Social do Conhecimento' e abrange trabalhos que buscam refletir sobre o papel das ciências físicas na cultura geral e investiga as características do conhecimento fora dos contextos científicos. Trabalhos anteriores analisaram aspectos ideológicos relacionados a como Einstein é representado na mídia, em especial em relatos de novas descobertas científicas. Também já buscamos compreender algumas apropriações da Física Quântica por obras que envolvem posturas místicas. Estes são assuntos de grande interesse e penetração sociais, que alimentam o imaginário das pessoas e são exemplos de como visões de ciências são criadas. Atualmente consideramos que uma das principais funções da educação científica é problematizar a ciência na mídia, o que envolve debater tanto a natureza das ciências quanto a natureza da mídia ${ }^{18}$.

\section{Referências}

ALlCHIN, D. Pseudohistory and Pseudoscience. Science \& Education, v.13, p. 179-185, abr. 2004.

AYLESWORTH, G. Postmodernism. In: Stanford Encyclopedia of Philosophy, 2015. p. 141.

BASILIO, S. G. A Ideologia em Materiais de Divulgação Científica: Um Estudo da Imagem de Einstein em Discursos sobre as Ondas Gravitacionais. 2018. 209 f. Dissertação (Mestrado em Ciências) - Instituto de Física, USP, São Paulo.

BAUMAN, Z. Modernidade Líquida. Rio de Janeiro: Zahar, 2001. 280 p.

BOURDIEU, P. Os Três Estados do Capital Cultural. In: Escritos de Educação. São Paulo: Vozes, 2015. cap. IV. p. 73-79.

BRUSH, S. G. Should the History of Science Be Rated X? Science, v. 183, p. 1164-1172, mar. 1974.

CARDOSO, D. Mídia, Ciência e Ensino: Problematizações na formação inicial de Professores de Física. 2019. 307 f. Tese (Doutorado em Ciências) - Instituto de Física, USP, São Paulo.

CARDOSO, D.; GURGEL, I. Por uma Educação Científica que Problematize a Mídia. Linhas Críticas, v. 25, n. 1, p. 74-93, abr. 2019.

18 Sobre aspectos ideológicos da imagem de Einstein Basilio (2018). Sobre misticismo quântico ver Saito (2019). Sobre Ciência e Mídia ver Cardoso (2019) e Cardoso e Gurgel (2019). 
CARSON, R. Primavera Silenciosa. São Paulo: Gaia, 2010. 328 p.

DIDEROT, D.; D’AlEMBERT. Discurso Preliminar da Enciclopédia. São Paulo: Ed. UNESP, 1989. 352 p.

FEYERABEND, P. Contra o Método. São Paulo: Ed. UNESP, 2011. 376 p.

FORATO, T. C. M. A Natureza da Ciência como Saber Escolar: Um Estudo de Caso a Partir da História da Luz. 2009. 220 f. Tese (Doutorado em Educação) - Faculdade de Educação, USP, São Paulo.

FORQUIN, J-C. Sociologie du Curriculum. Rennes: PUR, 2008. 197 p.

FORMAN, P. Weimar Culture, Causality, and Quantum Theory: adaptation by German physicists and mathematicians to a hostile environment. Historical Studies in the Physical Sciences, v. 3, p. 1-115, jan. 1971.

GALISON, P. L. Ten Problems in History and Philosophy of Science. Isis, v. 99, n. 1, p. 111124, mar. 2008.

GALISON, P. L. Einstein's Clocks, Poincaré's Maps: Empires of Time. New York: WW. Norton \& Company, 2003. 389 p.

GIDDENS, A. As Consequências da Modernidade. São Paulo: Ed. UNESP, 1991. 180 p.

GIDDENS, A.; SUTTON, P. Conceitos Essenciais da Sociologia. São Paulo: Ed. UNESP, 2015. $353 \mathrm{p}$.

GURGEL, I.; WATANABE, G. The Writing of the History of Science from the Notion of Scientific Field. Transversal: International Journal for the Historiography of Science, n. 8, p. 41-58, jun. 2020.

HABERMAS, J. Modernidade: Um Projeto Inacabado. In: ARANTES, O. B.; ARANTES, P. Um Ponto Cego do Projeto Moderno de Jürgen Habermas: arquitetura e dimensão estética depois das vanguardas. São Paulo: Brasiliense, 1992. 152p.

LATOUR, B. Jamais Fomos Modernos. São Paulo: Ed. 34, 2019. 192 p.

LYOTARD, J-F. A Condição Pós-Moderna. São Paulo: José Olympio, 1986. 152 p. 
MILNITSKY, R. Epistemologia e Currículo: Reflexões sobre a Ciência Contemporânea em Busca de um Outro Olhar para a Física de Partículas Elementares. 2018. 250 f. Dissertação (Mestrado em Ciências) - Instituto de Física, USP, São Paulo.

NORONHA, A. Dois Argumentos pelo Conhecimento sobre a Ciência no Ensino de Ciências: Por uma Contraideologia do Conflito e um Metaconhecimento Poderoso. Tese (Doutorado em Ciências) - Instituto de Física, USP, São Paulo, 2018. 220f.

NORONHA, A. Interpretando a Relatividade Especial: Discutindo o Debate Realismo e Antirrealismo Científicos no Ensino de Ciências. 2014. 381 f. Dissertação (Mestrado em Ciências) - Instituto de Física, USP, São Paulo.

ORTIZ, R. Universalismo e Diversidade. São Paulo: Boitempo, 2015. 176 p.

PESTRE, D. Introduction aux Science Studies. Paris: La Découverte, 2006. 122 p.

PIETROCOLA, M. Inovação Curricular e Gerenciamento de Riscos DidáticoPedagógicos: o ensino de conteúdos de Física Moderna e Contemporânea na escola média. Concurso de Professor Titular - Faculdade de Educação, USP, São Paulo, 2010. 50 f.

PIKETTY, T. O Capital o Século XXI. São Paulo: Intrínseca, 2014. 672 p.

ROBERTS, D. Scientific Literacy/Science Literacy. In: ABELL, S.K. e LEDERMAN, N.G. (Eds) Handbook of Research on Science Education. New Jersey: Lawrence Erlbaum Associates, 2007. cap. 25, p. 729-780.

ROBERTS, D. Developing the Concept of "Curriculum Emphases" in Science Education. Science Education, v. 66, n. 2, p. 243-260, 1982.

SAITO, M. T. A Gênese e o Desenvolvimento da Relação entre Física Quântica e Misticismo e suas Contribuições para o Ensino de Ciências. 2019. 356 f. Tese (Doutorado em Ciências) - Instituto de Física, USP, São Paulo.

STRIEDER, R. Abordagens CTS na Educação Científica no Brasil: sentidos e perspectivas. 2012. 283 f. Tese (Doutorado em Ciências) - Instituto de Física, USP, São Paulo. 
SEVCENKO, N. A Corrida para o Século XXI: No Loop da Montanha Russa. São Paulo: Cia das Letras, 2001. 144 p.

THORP, H. H. Persuasive Words Are Not Enough. Science, v. 368, n. 6498, p. 1405, jun. 2020.

WATANABE, G. A Divulgação Científica Produzida por Cientistas: contribuições para o capital cultural. 2015. 227 f. Tese (Doutorado em Ciências) - Instituto de Física, USP, São Paulo.

\author{
Ivã Gurgel ${ }^{19}$ \\ Grupo de Teoria e História dos Conhecimentos ${ }^{20}$ \\ Instituto de Física - USP
}

\footnotetext{
19 E-mail: gurgel@usp.br

20 Website: $\underline{\text { http://portal.if.usp.br/tehco/ }}$
} 